\title{
Fourier, One Man, Several Lives
}

Bernard Maurey (Sorbonne Université, Paris, France)

Fourier was born 250 years ago, twenty-one years before the French Revolution in 1789. The events of those troubled times turned his life into an adventure novel: the Revolution with its mortal dangers; Bonaparte's expedition to Egypt with its discoveries; later a political career as prefect of Isère at Grenoble, where Fourier wrote the first versions of the Théorie analytique de la chaleur, when he was not busy with the construction of the road from Grenoble to Turin or the drainage of marshland at Bourgoin; and finally, his academic role at the very heart of the Parisian scientific community during the years 1820-1830. While relating a variety of aspects which are not all of scientific concern, we shall, of course, dedicate an important space to the theory of heat, Fourier's major work, as well as to the Fourier series, which are a crucial element of his mathematics.

\section{Some books about Fourier}

Numerous authors have written about Fourier, especially from the second half of the $20^{\text {th }}$ century onwards, when several new works were published. Jean Dhombres and Jean-Bernard Robert have done a colossal work [D-R], which I did not hesitate to exploit, although often at the price of regrettable simplifications. A new work, under the direction of Dhombres, is to appear this year [Fo-R]; it aims at a broader public, contains a great number of illustrations and as yet unpublished archive material. Ivor Grattan-Guinness was the first to publish, in his 1972 book [GraF], the content of the essay Sur la propagation de la chaleur presented by Fourier at the Académie des Sciences in December 1807. Umberto Bottazzini [Bott] dedicated two sections ${ }^{1}$ to the study of the heat problem in the years 1800-1830. Another book I am going to refer to is the one by Jean-Pierre Kahane and Pierre Gilles LemariéRieusset $[\mathrm{K}-\mathrm{L}]$, the first part of which, written by Kahane, presents a history of Fourier series. The treatise on harmonic analysis by Thomas Körner [Körn] masterly sets out the mathematics attached to the name of Fourier. It also contains two small chapters on Fourier's life ${ }^{2}$, which are based mainly on the very informative book by John Herivel [Heri].

\section{The Revolution, the Egypt campaign}

Jean-Baptiste Joseph Fourier was born on 21 March 1768 in Auxerre. The baptism certificate bears Jean-Joseph as his first name. He was born into a family of craftsmen in social ascension: his father, a tailor, had about ten employees. At the age of ten, Jean-Joseph was orphaned and the clergy of Auxerre took care of him. There was a remote - and uncertain - family relationship with a beatified priest, so the abandonment of the boy was out of the question. He received a good education at the École Royale Militaire d'Auxerre, which was run by monks. After finishing school, at the age of 19, he applied for admittance to the entrance examination to the artillery, which was curtly refused him. "Not being noble", it was impossible for Fourier to become an artillery officer. So he turned to the religious orders and became a novice at the Benedictine Fleury Abbey in Saint-Benoît-sur-Loire. He lived there for two years, from 1787 to 1789 , and could have become Father Fourier, but the French Revolution broke out and the constituent Assemblée nationale issued decrees suspending the pronunciation of religious vows just before Fourier would pronounce his own in November 1789. Early in 1790, he returned to his former school in Auxerre, this time as a teacher. It was called "Collège National-École Militaire" at that time. He stayed there for four years, taught different subjects such as history, philosophy, eloquence and also mathematics, and became a "civil servant teacher".

Initially reserved towards the French Revolution, Fourier engaged in the Comité de surveillance of Auxerre at the beginning of '93 and even became its president in June ' 94 . He witnessed violent scenes of desecration of churches during the wave of dechristianising of 93-94, although we do not know what his feelings about it were. From September '93 onwards, the Comite d'Auxerre found itself in charge of executing the decisions of Maximilien de Robespierre and the Comité de Salut Public. Fourier, being rather moderate, might have been jeopardised by his lack of zeal in supporting the head cutters. Victor Cousin, his successor at the Académie française in 1831, reported in the Notes additionnelles à l'éloge de M. Fourier - years after the events - that Fourier had deliberately spoiled the arrest, in the town of Tonnerre, of a man sentenced to the scaffold. ${ }^{3}$ Nevertheless, Fourier signed a certain number of arrest warrants in the context of his competence in the Comité d'Auxerre. One event was to have led to his imprisonment: the "affaire d'Orléans", which is reported in great detail by Herivel. ${ }^{4}$

Early in October '93, Ichon, a member of the Convention, was despatched to collect weapons, equipment and horses in the Yonne and six surrounding départements, preparatory to certain operations in the Vendée. With this aim, he named six citizens of Auxerre - among them Fourier - for a one-month mission in Orléans from mid-October onwards. The city was troubled by the conflicts between sans-culottes and bourgeois. Laplanche, also a member of the Convention, had been sent there from Paris at the beginning of September. He first took revolutionary measures supposed to satisfy the sans-culottes, but then he did not resist the pressure from the richer classes and clashed with the leaders of the sans-culottes. Fourier opposed himself to Laplanche and, clearly exceeding the scope of his mission, supported the "left wing", as we would call it today. As a result, Laplanche and the authorities of Orléans requested Fourier's recall to Auxerre and denounced his be-

\footnotetext{
1 [Bott, 2.3, 2.4]

2 [Körn, part VI, ch. 92 and 93]
}

$\begin{array}{ll}3 & \text { [D-R, ch. III, p. 94] } \\ 4 & {[\text { Heri, 2.2] }}\end{array}$

EMS Newsletter September 2019 
haviour. Their complaint was transmitted to Paris. A decree from Paris relieved Fourier of all his duties on 29 October '93: "The Commission conferred [...] to the citizen Fournier [sic] is revoked; he is no longer authorised to receive such Commissions", and he was not permitted to carry out any more public functions. Ichon, who was responsible for Fourier's dispatch to Orléans, felt part of the blame reflecting on him; in his fury, he issued an arrest warrant against Fourier, who fortunately had not returned to town yet. As things had calmed down a bit by his return to Auxerre, he was left in peace. Meanwhile, the Orléans affair ended up reappearing in Paris. With Robespierre fighting to his left as well as to his right, the agitators from Orléans were targeted, and so was Fourier. On 19 June '94, the Comité de Sûreté Générale ordered his arrest (it was the very June the "Grande Terreur" law was adopted). We know today [Fo-R] that Fourier was not imprisoned, he benefitted from privileged treatment and was put under house arrest on 4 July at his home in Auxerre. Robespierre fell at the end of July and Fourier was "freed" on 11 August.

At the end of ' 94 , Fourier was selected as one of the young teachers to be trained at the newly established École Normale, the "École Normale de l'an III". The institution lasted only one semester, from January to June '95. Fourier was a distinguished student, but because of political changes, his former participation in the Jacobin committee got him into trouble. In times of the Thermidorian Reaction, a hunt for "terrorists" was taking place. The new authorities in Auxerre wanted Fourier to be expelled from the École Normale; they reproached him with his past in an address to the Convention Nationale: ${ }^{5}$

We, the Representatives, shudder when we consider that the pupils of the Écoles Normales have been chosen under the rule of Robespierre and by his protégés; it is only too true that Balme and Fourrier [sic], pupils from the Yonne department, have for a long time uttered the appalling principles and the infernal maxims of the tyrants.

At the beginning of June '95, Fourier was imprisoned. After a few days he obtained a conditional release order, but the order was not followed and he stayed in prison for a month or more. At the end of August he was freed, his judicial troubles finally settled and all his civil rights restored.

The first years of the Revolution were certainly dangerous, though undoubtedly exciting, too. Kahane ${ }^{6}$ cites a passage from a letter Fourier wrote:

As the natural ideas of equality were developing it became possible to conceive the sublime hope to establish among us a free government without kings nor priests and to take this double yoke away from the European soil that had been usurped for so long.

And yet it was thanks to the education he received from the Benedictines at the École Royale Militaire of Auxerre that he was able to write beautiful sentences like the one we just cited, and the institution made a teacher out of him. The above extract is taken from a long letter written in the summer of '95 to Edmé-Pierre-Alexandre Villetard, deputy of the

5 [D-R, ch. IV, p. 150]

6 [K-L, ch. 1, p. 8]
Yonne (reproduced by Dhombres and Robert ${ }^{7}$ ), under the circumstances mentioned above, when Fourier tried to justify his behaviour in the years '93-'94, his integrity being questioned.

As an outstanding student of the École Normale, he attracted the attention of Gaspard Monge, he attended lectures of Pierre-Simon Laplace and of the eminent Joseph-Louis Lagrange, "the first among Europe's scholars", as Fourier wrote in his Notes sur l'École Normale. ${ }^{8}$ Laplace, an acknowledged scientist under the Ancien Régime, had to seclude himself during the Terreur; in '95, he reappeared on the scene and quickly became very influential. Fourier mentioned in his Notes that he also attended lectures on physics by René-Just Haüy, on chemistry by Claude-Louis Berthollet as well as the lectures by the - very old - naturalist Louis Jean-Marie d'Aubenton (I am citing only the most well known). When the École Normale was closed, Fourier became a teacher at the École Polytechnique (which we are going to refer to simply as "the École" in the following; before September '95 it was called École Centrale des Travaux Publics). Recommended by Monge, he became substitut at the École at the end of May ' 95 - his mission consisted of supervising the students' works -, then assistant teacher in October '95. For over two years, he deeply committed himself to his duties as a mathematics teacher.

One can get an impression of the lectures held by Fourier from 1796 to 1797 from the notes taken by students, ${ }^{9}$ which are kept at the Institut de France and at the École des Ponts et Chaussées. ${ }^{10}$ These lectures were not based on the manuals from the $18^{\text {th }}$ century (like the treatise by Étienne Bézout), but rather inspired by Lagrange and Laplace's lectures given at the École Normale; also the geometric spirit of Monge is discernible. From November '95 onwards, Fourier was in charge of the lectures on Algebraic Analysis, which prepared for the lectures on differential calculus. In January '96 he took over part of Prony's Analysis lectures, including the calculus of variations. In March '96, he showed the students the existence of complex roots of polynomials by means of the method presented by Laplace at the École Normale [Éc-N]. Laplace's proof applies to the case of real coefficients; it puts the degree $n$ of the polynomial into the form $n=2^{i} s$ where $s$ is odd, and proceeds by a subtle recurrence on $i$, the case $i=0$ being determined by the property of the intermediate values - taken as evident. Fourier simplified and generalised a bit: if we suppose that the polynomials with complex coefficients of odd degree have a complex root, we can factor them into complex factors of first degree. In May '96, he treated differential and integral calculus. In '97, he succeeded Lagrange in the chair of Analysis and Mechanics. He could have occupied it for many years, like several others did. However, political events were to divert the course of his existence.

The expedition to Egypt was a pivotal episode in Fourier's life. Early in '98, the authorities of the Directoire exécutif enjoined him to take part in an operation that was surrounded by secrets: by then, only few of its members knew the exact destination. At the end of March '98, Fourier left Paris, as did some

\footnotetext{
7 [D-R, Annexe IV, p. 709]

8 [D-R, Annexe II]

9 [D-R, ch. IV, p. 158]

10 [GraF, ch. 1, p. 6-7]
} 
forty current and former students of the École, out of the graduates '94 (the first year) to '97, whose teacher Fourier might have been. Among them, Jean-Baptiste Prosper Jollois and Édouard de Villiers du Terrage ("Devilliers" at the École, a tribute to the Revolution), engineer and future engineer of the Ponts et Chaussées corps, aged 22 and 18. They would write many pages of the monumental work Description de l'Égypte, which, published from 1809 on, would record the discoveries of the expedition through the texts and illustrations from numerous contributors; Fourier would contribute with a long preface. Among the illustrators are Vivant Denon and HenriJoseph Redouté (painter, brother of Pierre-Joseph Redouté, who is known for his watercolour paintings of roses). Scientists and engineers like Monge, Berthollet, Étienne Geoffroy Saint-Hilaire, Nicolas-Jacques Conté and Pierre-Simon Girard also took part in the journey. Back in France, Girard, chief engineer of the Ponts et Chaussées corps, would direct the construction of the Ourcq canal; under his orders in 1809: the young Augustin Louis Cauchy, 20 years old, aspiring engineer at Ponts et Chaussées.

Fourier boarded in Toulon in mid-May. An expeditionary corps of over 30,000 men set off from France and Italy. The Egypt campaign was not easy: among many other victims, 7 of $42^{11}$ young polytechnicians would never come back. The expedition landed at Alexandria, early in July. At the beginning of August, in Rosetta (the place where the famous stone was found in July '99, at about $50 \mathrm{~km}$ from Alexandria), Fourier became responsible for the Courrier de l'Égypte, a newspaper with the mission to promote the engagement of the general-in-chief Napoléon Bonaparte. At the end of August '98, he was named permanent secretary of the Institut d'Égypte created in Cairo by Bonaparte. He played an administrative as well as a political role, especially when it came to negotiations with the local authorities. Dhombres and Robert point out that when Bonaparte engaged in Syria (FebruaryJune '99), Fourier found himself as the de facto governor of Lower Egypt, without officially holding the title. When Bonaparte (and Monge) returned to France in August '99, he remained the principal civil authority, in particular after the death of General Jean-Baptiste Kléber who had been assassinated in Cairo in June 1800 and whose eulogy had been given by Fourier (he knew how to write speeches and was a good orator). He ensured the link between the civilians and the servicemen of the expedition. He negotiated again when the adventure came to an end when General Menou surrendered in September 1801, this time with the English who held the Egyptian harbours, in order to obtain for the French scientists the right to leave under the best possible conditions, keeping the essential parts of their notes and discoveries. Nevertheless, the Rosetta stone would be sent to England, where it is still kept today.

Fourier's activity in Egypt was not limited to administration and politics. In October '98, he acted as examiner of the École Polytechnique: together with Monge, he questioned students who graduated in ' 96 and came to Egypt. He participated in scientific and archeological expeditions, namely in Upper Egypt in September-October '99. He led mathematical research, presented several communications at the Insti-

11 [Mass, annexe] tut d'Égypte on algebraic subjects, rather minor works which were not published, and also a Mémoire sur l'analyse indéterminée, judged more convincing by Dhombres-Robert [D-R] and Grattan-Guinness [GraF], who understand it as a forerunner of what we call linear programming. Fourier would pick up this question again, much later, in communications at the Académie des Sciences in 1823 - in order to simplify, we name Académie des Sciences the institution which has also been called Académie Royale des Sciences or Classe des Sciences de l'Institut - as well as in an article from 1826 in the Bulletin des Sciences, par la Société philomathique.

\section{Grenoble, Paris, the work}

On his return from Egypt, Fourier landed in Toulon in November 1801 and returned to Paris in early January 1802, where he briefly went back to the École Polytechnique. However, Napoleon then sent him to Grenoble as prefect of the Isère department in 1802 after the death of the previous prefect, Gabriel Ricard. Fourier accepted the position and arrived in mid-April. It is possible that this was partially an aggravation, but there was also a need to fill the role with a capable and dependable person: qualities that Fourier demonstrated in Egypt. In Grenoble, he began work on the Theory of Heat and in 1805 , he wrote an unpublished essay that was a sort of first draft of the theory. At the end of 1807, he presented a first essay on the propagation of heat to the Académie. The four "examiners" recorded in the minutes of the meeting on 21 December were Lagrange, Laplace, Monge and Sylvestre Lacroix. The text was not well received by Lagrange, ${ }^{12,} 13$ and had a slightly better reception with Laplace who, in a memoir of 1809-1810 [Lapl], attributed to Fourier the discovery of the heat equation.

Fourier's 1807 essay, still unpublished, was published and commented on by Grattan-Guinness in 1972 [GraF]. It was kept at the École nationale des Ponts et Chaussées, where Claude Louis Marie Henri Navier, a friend of Fourier's, was a professor. Navier was the "executor" of Fourier's manuscripts. Gaston Darboux, the editor of Fourier's CEuvres (Works - published in 1888 and 1890), discovered the essay at the end of the $1880 \mathrm{~s}$, but did not make use of it. Attached to the "Essay" were documents sent by Fourier to the Académie in 1808 and 1809; these showed that he had been made aware of the objections of the examiners and that he had responded. Included in these documents were an Extrait submitted in 1809 (only the first ten pages have been preserved) that is a short non-mathematic presentation of the essay's content, and a ten-page collection of Notes responding to the objections. ${ }^{14}$

The Académie remained silent on the work presented by Fourier in 1807. A rather cold summary by Siméon Denis Poisson, published in the Bulletin des Sciences in March 1808, mentioned the heat equation, but not the processing by means of "Fourier series". In 1809, Fourier finished writing the Préface Historique to the Description de l'Égypte (Historic Introduction to the Description of Egypt). This com-

12 [GraF, p. 24, end of ch. 1]

13 [Bott, Note $\left(^{5}\right)$ for ch. 2]

14 [GraF, ch. 1, p. 24] 
position hung over him at a time when his mind was occupied with heat and he wanted to see his 1807 essay recognised. The Préface, an impressive document of 90 pages, was checked over by Napoleon; Fourier "travelled up" to Paris to present his work. He had to be a historian to report on the history of Egypt, both ancient and contemporary, a stylist to deliver a text that he considered flawless and a diplomat to know how he had to describe the actions taken in Egypt by the man who was now the Emperor. Körner states that an Egyptologist of his acquaintance considers this Préface to be "a masterpiece and a turning point in the subject", ${ }^{15}$ and that this Egyptologist was surprised to learn that the author was also equally well known as a mathematician! In order to carry out his task, Fourier was assisted by Jacques-Joseph Champollion-Figeac, who was passionate about Egyptology. His younger brother, Jean-François, who was born in 1790 and was a pupil at the lycée impérial in Grenoble in 1804, the same year it was established, was an enthusiast of ancient languages, and had a small part in preparing the Préface. Jean-François Champollion began deciphering hieroglyphics in 1822. After his death in 1832, he was buried - in accordance with his wishes - near to Fourier (who was also buried not far from Monge) in the Père-Lachaise Cemetery in Paris.

In 1811, Fourier significantly reworked his 1807 text and was finally awarded a prize by the Académie in January 1812. Lagrange continued to oppose him (he died the following year). The report awarding this prize was not without its reservations, "[...] the way in which the author reaches his equations is not without its difficulties and [...] his analysis to integrate them leaves something to be desired, as regards the level of generality or even on the side of rigor". Although honoured by the prize, Fourier was offended, he protested to the permanent secretary for mathematical sciences, JeanBaptiste Joseph Delambre, but there was not much to be done. The following years brought major political upheaval that occupied and affected the prefect of Isère: 1814 and 1815 saw Napoleon's first exile, then his return from the island of Elba and his downfall.

After Napoleon's defeat in Russia, it was French territory that was threatened from the end of 1813 by a coalition primarily made up of Britain, Austria, Prussia and Russia. Henry Beyle, 30 years old and not yet known as the writer Stendhal, was attached to the Conseil d'État (Council of State) during the war. He was sent to Dauphiné in November 1813 in order to assist the special commissioner responsible for the measures to be taken to protect the region. In January 1814, Grenoble feared the arrival of the Austrian forces that had taken Geneva. The prefect had to organise the defence with the help of the military and Stendhal. Stendhal did not like Fourier, who, in his opinion, delayed and hindered military action; he had particularly contemptuous words for the prefect: "One of the causes for my trouble in Grenoble was the little intellectual scientist with practically no character and the low manners of a decorated servant, named Fourier". ${ }^{16}$ Paris fell on 31 March and Napoleon abdicated on 6 April. On 12 April, he signed the Treaty of Fontainebleau and departed for his new kingdom, the island of Elba. With Austrian

15 [Körn, end of ch. 92]

16 [D-R, ch. VI, p. 347] troops in Grenoble, Fourier and the majority of his prefecture rallied behind the First Restoration on 16 April. Napoleon's route took him close to Grenoble, to the great discomfort of Fourier, who was to have almost another year in his role as prefect.

In 1815, on his return from Elba, Napoleon entered Grenoble and Fourier left to avoid him. After having suspended him and threatened him with arrest on 9 March, Napoleon reconsidered and named him prefect of the Rhône department on 11 March. Fourier began work again at his new post but it ended with his refusal to apply the purging measures set by Napoleon and his Ministry of the Interior Lazare Carnot being the Minister of the Interior - and he was dismissed on 3 May 1815.

During the Second Restoration, Fourier's pension was taken away as he was too well known as having served in the Napoleonic regime, particularly for his participation in the Hundred Days. He then received welcome support from the prefect of the Seine, Gaspard Chabrol de Volvic. Chabrol was a former student of the École (class of 1794), had had Fourier as a teacher and, furthermore, had been in Egypt. He was already the prefect of the Seine under Napoleon, but did not participate in the Hundred Days and remained in the same role until 1830. Chabrol entrusted Fourier with managing the statistical office for the Seine department. Fourier dedicated himself to this task with great interest and published Recherches statistiques sur la Ville de Paris et le département de la Seine (Statistical research on the city of Paris and the Seine department) in four volumes between 1821 and 1829. These were far from the theoretical works on probabilities or statistics by Laplace, but Körner mentions that some demographers know Fourier only as the man who played a significant role in the development of government statistics in France. ${ }^{17}$

In 1817 , the political upheavals had abated and Fourier was elected a member of the Académie after an initial candidacy and an election in 1816 that was not approved by King Louis XVIII. He became the permanent secretary of the Académie des Sciences five years later, after the death of Delambre. As a leading member of the Académie, he had the opportunity to be in contact with Sophie Germain and they exchanged letters regularly between 1820 and 1827; he obtained spaces for her to attend the Institut's public meetings, he supported her against Poisson, who was also working on the theory of elastic surfaces, and she backed him for the post of permanent secretary in 1822. It is thought that Laplace, in his old age (he was 73 years old in 1822), became closer to Fourier and also supported him. Fourier gave a eulogy for Laplace (deceased in 1827), again a fine speech. In 1822, he edited the definitive version of the Analytical Theory of Heat, and his essay from 1811 was finally published in 1824 ! He was elected to the Académie française in 1826, although the decision was not unanimously appreciated, as it is true that his literary work was somewhat meagre.

The end of Fourier's life was difficult due to ill health. He suffered from chronic rheumatism (also whilst in Grenoble) and may have contracted a tropical disease in Egypt; he became extremely sensitive to the cold, as Grattan-Guinness ${ }^{18}$

17 [Körn, end of ch. 93]

18 [GraF, end of ch. 22] 
comments: "[illness] caused him to discourage the diffusion of heat in his quarters", to the point where he wore thick woollen clothes and ran the heating in all seasons. Throughout these years, he was absent from many of the Académie's meetings. His final months were especially difficult and he spent his days in a special chair ${ }^{19}$ from which he was still able to work. The disease may have also diminished his intellectual faculties when the permanent secretary should have taken better care of the famous essay by Évariste Galois, presented in 1829 and then in 1830. Fourier died on 16 May 1830 in Paris at the age of 62.

For us, Fourier is primarily the man of a unique work, the theory of heat. He published several lesser-known works, including essays on statics in 1798 (an article on rational mechanics, including three proofs of the principle of virtual work using the concept of moment) and on statistics between 1821 and 1829. He left a mass of manuscripts, many of which can be found in the National Library of France. One particular topic must be mentioned: for a very long period of time, Fourier conducted research on determining the number of real roots of a polynomial that are in a given interval, and on the methods of calculating values close to these roots. The question had already interested him in 1787 and even throughout his earlier years [Fo-R]. On 9 December 1789, he presented a statement to the Académie on this subject, which he also focused on in his lessons at the École in 1796 and 1797 and which he worked on in Egypt and then in Grenoble in 1804. These clarifications were given by Navier, see below. Fourier published several articles in the same vein from 1818 and submitted communications to the Académie between 1820 and 1830 . His research led to a higher limit for the number of roots. In 1829, Jacques Charles-François Sturm discovered the theorem that is now named after him (his essay was published in 1835) and that allowed him to find the exact number of roots. Sturm stated that "the theorem that is developed throughout this essay is greatly similar to that of Fourier".

In his final years, Fourier started a work titled "Analyse des équations déterminées" (Analysis of determinate equations) that he was unable to finish; it was meant to bring together in two volumes the algebraic works mentioned above. Navier went on to publish the existing parts in 1831 and he wrote a "Foreword by the editor" of 24 pages that aimed to confirm Fourier's precedence over results that were more than 40 years old. Navier cited the documents in his possession; he paid particular attention to a pre-1789 manuscript Recherches sur l'algèbre (Research on algebra) attributed to Fourier (but not by his hand and incomplete, with only the first 28 pages remaining), and mentioned notes taken by a student during Fourier's lessons at the École in 1797, then a text written in Grenoble in 1804. He also concentrated on the existence of accounts that made it possible to date each of these documents. Precedence was contested by François Budan de Boislaurent, who became a doctor of medicine in 1803 and general inspector of public instruction in 1808. He was a skilled mathematician, although an "amateur"; he submitted an essay to the Académie in 1803, published an article in 1807 and a book in 1822 on the same question of the number of roots. ${ }^{20}$

19 [GraF, end of ch. 22]

20 see Jacques Borowczyk [Boro]
The dispute was very heated, even if it is not as important today. If Fourier's analytical method led to Sturm's result, it was that of Budan, which is combinatorial and of an algorithmic nature, that has had consequences in algebraic computation nowadays.

\section{Trigonometric series}

It was, of course, not Fourier who invented the trigonometric series: Leonhard Euler, Daniel Bernoulli and many others had used them before him. We may need to go back to Brook Taylor, the man of the Taylor formula, one of the first to link, around 1715, the vibration of cords to sinusoidal curves, which at the time were called "companion of the cycloid". But Fourier gave some beautiful examples of such series, and above all, systematised the relation between "function" and "Fourier series". By doing so, he helped to modify and specify the conception of functions in mathematics, a task to be completed about twenty years later by Dirichlet. Fourier calculated a large number of trigonometric series expansions of $2 \pi$ periodic, not necessarily continuous functions, some of which already figured in his essay from 1805 . He rediscovered the expansion of the function equal to $x$ when $|x|<\pi$, mentioning of course that it was Euler's due, and clearly stating ${ }^{21}$ the need to limit its validity to $|x|<\pi$, he expanded in a sine series the odd function which equals $\cos x$ for $0<x<\pi$ (a fact that shocked Lagrange and even Laplace), also the function which equals $\sinh x$ for $|x|<\pi$, and many others. Reading the book by Grattan-Guiness [GraF] one realises the vastness of the mathematical content in Fourier's works on heat. In the following, I would like to dwell on an example which is undoubtedly the most famous one.

After having explained the physical principles needed to understand the temperature evolution in bodies and having established the heat equation inside a solid:

$$
\frac{\partial v}{\partial t}=\kappa \Delta v, \quad \kappa>0,
$$

Fourier proposes ${ }^{22}$ to explicitly determine the equilibrium temperature $v(x, y, z)$ in an infinite solid limited by two parallel planes and a third one perpendicular to the two others, supposing a fixed temperature at the edge. The solid is put into equation so that the geometry and the temperature do not depend on the coordinate $z$ : in art. 165 , it is restricted to a problem in $x, y$, namely a rectangular blade which is modelised by the set $\{(x, y): x \geqslant 0,|y| \leqslant \pi / 2\}$. At the edge, the temperature $v$ equals 1 when $x=0$ and $|y|<\pi / 2$, or 0 when $x \geqslant 0$ and $|y|=\pi / 2$. The equilibrium equation in the blade is $\Delta v=0$. The condition at the edge being even in $y$, Fourier searches for solutions that are even in $y$ : he considers a solution that combines functions $\mathrm{e}^{-k x} \cos (k y)$, where the fact that $v$ is zero in the case $|y|=\pi / 2$ imposes that $k$ is an odd integer, and where we have $k>0$, for reasons of physical likelihood. ${ }^{23}$ The method of separated variables had already been used by Jean d'Alembert and Euler, the superposition (even of an infinity) of solutions by Bernoulli. So Fourier searches for a $v$

21 for example, [Fo-C, art. 184]

22 [Fo-C, ch. III, art. 163, p. 159 and next.]

23 [Fo-P, art. 33], to be found in [GraF, p. 138] 
of the following form:

$$
v(x, y)=a \mathrm{e}^{-x} \cos y+b \mathrm{e}^{-3 x} \cos 3 y+c \mathrm{e}^{-5 x} \cos 5 y+\cdots
$$

The condition $v=1$ for $x=0$ makes him try to find an expansion which satisfies

$$
1=a \cos y+b \cos 3 y+c \cos 5 y+\cdots
$$

when $|y|<\pi / 2$. He first determinates the coefficient $a$ of $\cos y$, then finds analogously the following coefficients $b, c, \ldots$ To achieve this, he takes derivatives of equation (1) an even number of times and writes for any integer $j>0$ the identity

$$
0=a \cos y+b 3^{2 j} \cos 3 y+c 5^{2 j} \cos 5 y+\cdots .
$$

To calculate the coefficients, Fourier supposes, as a first step, a limited number of $m$ unknowns $a, b, \ldots, r$, and considers a system of $m$ equations, the first one resulting from (1) while the $m-1$ other ones, i.e., for $j=1, \ldots, m-1$, are

$$
\begin{aligned}
0=a \cos y+b 3^{2 j} \cos 3 y+c 5^{2 j} \cos 5 y+\cdots & \\
& +r(2 m-1)^{2 j} \cos (2 m-1) y .
\end{aligned}
$$

Putting $y=0$, he obtains a Vandermonde system, which he solves in order to find an approximate value $a^{(m)}$ to the solution $a$, and takes the limit with $m$ using the Wallis product formula that provides $a=4 / \pi$.

Going a bit more into detail, using $x_{1}, \ldots, x_{m}$ instead of $a, b, \ldots, r$, and setting $k_{i}=(2 i-1)^{2}, i=1, \ldots, m$, the $m$ equations considered by Fourier are

$$
k_{1}^{j} x_{1}+k_{2}^{j} x_{2}+\cdots+k_{m}^{j} x_{m}=\delta_{j, 0}, \quad j=0, \ldots, m-1,
$$

where $\delta_{j, 0}$ is the Kronecker symbol. Fourier calculates "by hand", filling four pages, but we can make use of Cramer's rule that expresses $x_{1}$, the approximate value $a^{(m)}$ at step $m$, with the help of a quotient of two Vandermonde determinants,

$$
\begin{aligned}
x_{1} & =\frac{k_{2} \ldots k_{m} \prod_{1<i<\ell \leqslant m}\left(k_{\ell}-k_{i}\right)}{\prod_{1 \leqslant i<\ell \leqslant m}\left(k_{\ell}-k_{i}\right)} \\
& =\frac{k_{2} \ldots k_{m}}{\prod_{1<\ell \leqslant m}\left(k_{\ell}-1\right)} \\
& =\frac{3.3 .5 .5 \ldots(2 m-1)(2 m-1)}{2.4 .4 .6 \ldots(2 m-2)(2 m)},
\end{aligned}
$$

which leads us to Wallis. The calculation for $x_{2}, x_{3}, \ldots$ is analogous.

Fourier remarks further that the value 1 on the left of equation (1) will change into -1 if we add $\pi$ to $y$. This essential remark makes him understand which are the values of the $2 \pi$ periodic extension of the sum of his series, constant on the interval $(-\pi / 2, \pi / 2)$ : he has obtained ${ }^{24}$ the trigonometric series development of a "crenel function",

$$
\frac{\pi}{4} \operatorname{sign}(\cos y)=\cos y-\frac{1}{3} \cos 3 y+\frac{1}{5} \cos 5 y-\frac{1}{7} \cos 7 y+\cdots \text {. }
$$

The formula already figures in the manuscript from 1805 and the study from 1822 of this problem can also be found in the dissertation from $1807 .{ }^{25}$ Further on in the text, Fourier comes to the "Fourier" integral formulas for the calculation

24 [Fo-C, ch. III, art. 177-180]

25 [Fo-P, art. 32-43] of coefficients. He had not used them in the previous example, where he applied the computational method described above. Then, again using the same lines of argument, he establishes the integral formulas, at least initially. Considered a flaw by some, a quality by others, Fourier is not concise: he sets about a long proof. Beginning at art. 207, first article of Section VI, Développement d'une fonction arbitraire en séries trigonométriques [Fo-C] he starts from an odd periodic function and writes its development in Taylor series at 0 , which is supposed to exist. Equating the Taylor series to the trigonometric (sine) series found for this same function, he calculates the "Fourier" coefficients with the help of equations that look like the ones he gave in the case of the crenel function. This leads to art. 218, the integrals appearing in art. 219. Fourier does not restrict himself to only one proof: in art. 221, he finally proposes to multiply the sum of the trigonometric series by $\sin n x$ and integrate term by term from 0 to $\pi$, using the orthogonality which will play such a fundamental role in analysis. He uses this method at least from 1807 on; ${ }^{26}$ the issue, though, is not yet the justification of the integration term by term. In his progressive and "pedagogical" approach, he started from a regular function to apply the first proof (which, to a small extent, could prove the existence of the development), and he notes in the end that he is now, with the help of the integral formulas, able to analyse "general" functions.

Back to physics, Fourier gives many examples "limited" in space, one of them being the case of the armilla, a metal ring (ch. IV). The study of heat in a cylinder of infinite length leads to Bessel functions; they were presented by Friedrich Bessel in 1816-1817 at the Berlin Academy and published in 1819 , but Fourier had studied this example since 1807 [GraF, ch. 15 et 16] and written the power series of $J_{0}$ long before Bessel's publication (although after Euler, in 1766 and $1784^{27}$ ). Fourier solves by power series the differential equation $u^{\prime \prime}+u^{\prime} / x+\kappa u=0(\kappa>0, u$ is linked to the Bessel function $J_{0}$ by $u(x)=c J_{0}(\sqrt{\kappa} x)$ ), and uses this to produce, for the cylinder, eigenmodes - he called them "modes propres" - that are orthogonal. The constant $\kappa$ is determined by the condition (7) on the surface of the cylinder (given further on), which provides a series of possible values, linked to the solutions $\kappa_{i}>0$ of an equation of the form $J_{0}\left(\sqrt{\kappa_{i}} r\right)+\sqrt{\kappa_{i}} J_{0}^{\prime}\left(\sqrt{\kappa_{i}} r\right)=0, r>0$ being the radius of the cylinder. Finally, the case of unlimited space, omitted in 1807, reveals the Fourier transformation on the real line: it appears in the awarded dissertation from 1812 (art. 71) and in article 346 of the last chapter of the book from 1822 with its inverse transformation. That chapter IX is simply entitled De la diffusion de la chaleur (On the diffusion of heat).

It seems difficult for the amateur historian to evaluate the proof that lead to the equation (3) giving the crenel function and which used arguments that might be considered totally wrong according to rigorous criteria: the derived series (2) given by Fourier are grossly divergent; it is comprehensible that mathematicians from the mid- $19^{\text {th }}$ century may have not taken his mathematics seriously. Today one can say that those series converge in the sense of distributions, but Fourier used

26 [Fo-P, art. 63]

27 [GraC, 3.4.4, 9.2.8] 
the pointwise value of partial sums. Kahane ${ }^{28}$ sees it as the search for trigonometric polynomials that become more and more "flat" at 0 and which converge towards the solution. One is tempted to state that Fourier has been lucky in that matter. And even then! As he liked to accumulate concordant evidence, he explicitly calculated the derivative of the partial sum of (1), when one replaces the undetermined coefficients $a, b, c, \ldots$ by the obtained values; this derivative is equal to $(-1)^{m} \sin (2 m x) /(2 \cos x)$, and he deduced that the antiderivatives, partial sums of (1), were more and more close to constant functions on $(-\pi / 2, \pi / 2){ }^{29}$

Niels Henrik Abel [AbeU] and Peter Gustav Lejeune Dirichlet [DirC] soon came to bring more rigour into the processing of function series. Abel had not, strictly speaking, considered trigonometric series in his paper from 1826 (which he wrote in French. ${ }^{30}$ It has been translated into German by August Leopold Crelle, the "chief" of the Journal für die reine und angewandte Mathematik, see [AbeO, préface p. III], see also Bottazzini [Bott, 3.1] for a review of the article). Abel, on the occasion of studying Newton's binomial series, which he considered not to be sufficiently justified by Cauchy (although he praised the treatise on Analysis by the latter), established principles for the study of function series, in particular for the power series of a complex variable, the continuity of which he proved in the open disc of convergence. Moreover, Abel also wrote the complex number $z=a+\mathrm{i} b$ as $z=r(\cos \varphi+\mathrm{i} \sin \varphi)$ and then obtained Fourier series. Unfortunately, his good principles did not prevent him from making too optimistic statements that turned out to be false. ${ }^{31}$

\section{$4 \quad$ Competition for heat, enmities}

The study of heat was a serious subject around 1800, especially with the rise of the steam engine. Jean-Baptiste Biot, a student of the first graduation class in the École polytechnique in 1794, and later close to Laplace, was a member of the Institut from 1803. He is still known mainly for the BiotSavart Law (1820), as well as for the law on the rotation of polarised light passing through a liquid (1835). In 1804, he published an essay on the propagation of heat (Mémoire sur la propagation de la chaleur) $[\mathrm{BioM}] .{ }^{32}$ In this essay, which is very reverential with regard to "Mr Laplace", he deals with the temperature equilibrium in a bar that is heated at the end, a subject that had already been studied extensively in several European countries, both through experimentation and with attempts at mathematisation. We can cite the book by mathematician and physicist Johann Heinrich Lambert Pyrometrie oder vom Maaße des Feuers und der Wärme (Pyrometry, or the measurement of fire and heat), which was published in 1779 , two years after his death. This book was printed in a Gothic script, which does not help us, and was therefore little-read in France and had a correspondingly weak impact. It is also necessary to refer back to an (anonymous) article

\footnotetext{
$28[\mathrm{~K}-\mathrm{L}, 2.4]$

29 [Fo-P, art. 43]

30 [AbeO, XIV, p. 219]

31 [Bott, 3.5]

32 [Bott, 2.3.a]
}

by Isaac Newton in 1701 that sets an initial principle that one can summarise as follows: the temperature of a warm body, cooled in a constant and low-temperature air current, is a decreasing exponential function of time.

Biot described his experiment, stating that it is not possible to noticeably heat the end of an iron bar that is $2 \mathrm{~m}$ long by $3 \mathrm{~cm}$ in the cross-section if the other end is placed in an intense fire. In the temperature equilibrium, he found an exponential decay in the temperature of points of the bar when one moves away from the source, putting forward a verbal mathematical proof, but he did not write an equation. He explained the equilibrium that occurs at each point of the bar between the heat received from the source, the heat transferred to the further points of the bar and the heat lost at the surface, but without writing a formula. He also did not cite Lambert, even if these considerations were practically identical to those in art. 326 of the latter. ${ }^{33}$

Biot mentioned that the results depend on a second order differential equation (one can think that it takes the form $u^{\prime \prime}=\kappa u, \kappa>0$ ), where the quotient of the radiance and conductivity of the bar appears, two coefficients that he differentiates between, measuring loss towards the surface and internal conduction. He indicates, without a formula, that the usual solution to the differential equation (in $a \mathrm{e}^{\sqrt{\kappa} x}+b \mathrm{e}^{-\sqrt{\kappa} x}$ ) includes only one term here as it must stay bounded when $x$ becomes large (positive). In addition, he highlights using only words that the mathematical process leads, outside the equilibrium state, to a second order partial differential equation involving time. In order to evaluate the temperature of a very hot source, Biot also suggested applying the exponential law discovered: using a bar that has one end touching the source, too hot for a thermometer, it is possible to measure the temperature of a point of the bar that is suitably far from this end and to therefore deduce the temperature of the heat source.

Fourier's first essay from 1805 already included general equations for the propagation of heat but it was not published. Rather, these were personal notes totalling some 80 pages. Fourier went much further than Biot: he dealt with equilibrium temperatures $v(x, y)$ or $v(x, y, z)$ that depend on several space variables and also looked at the variation with time. However, he wrote the differential equation (4) below, simply in $x$, for the temperature equilibrium of a bar heated at one end and he politely mentioned ${ }^{34}$ Biot's work from 1804. In this essay, the heat equation was not yet in its correct form as Fourier included in the equation inside a solid the $h\left(v-v_{e}\right)$ term of the equation (7) given below. This term should only appear on the surface. ${ }^{35}$ Even so, it can be seen in a note added to the margin that he was not sure that this term should be present. ${ }^{36}$ The formalisation of the physical phenomenon was still not satisfactory: ${ }^{37}$ Biot and Fourier struggled with differential homogeneity in the infinitesimal analysis of the problem, an "analytical difficulty" that Fourier circumvented then with an artificial contortion. On the other hand, the essay includes accomplished mathematical sections. There are sev-

\footnotetext{
33 [Heri, 8.1, p. 163]

34 [GraF, end of ch. 8, p. 186]

35 [Bott, end of 2.3.a, p. 65-66]

36 [GraF, ch. 5, p. 111]

37 [Heri, 8.1, p. 164-165]
} 
eral developments in trigonometric series ${ }^{38}$ that Fourier will present again later on, including the crenel function and the sawtooth function.

In his essay submitted to the Académie [Fo-P] in 1807, Fourier gave for the temperature equilibrium $v$ of the "Biot bar" the equation

$$
\frac{\partial^{2} v}{\partial x^{2}}=\frac{2 h}{K \ell} v
$$

which involved the width $\ell / 2$ of the bar. And Biot's name disappeared, for reasons I was unable to discover. At that time, Fourier applied a physical analysis that he (almost) did not change later, by presenting his concept of heat flow (which resolved his problem of homogeneity). Biot's analysis took into account conductivities $h, K-$ in the quotient mentioned by Biot and referenced above - , but it did not account for $\ell$. Later, Fourier, feeling mistreated by Biot, took pleasure in insisting on several occasions in his correspondence on "the mistake" of the latter: it was incorrect to claim that a 2-metre-long iron rod heated at one end could not be heated at the other end if it has a small cross-section.

Biot was an excellent scientist but Fourier often treated him with disdain. They were not on the same side, either politically or ideologically - Biot was a conservative Catholic -, and on several occasions, Biot disparaged Fourier's work. This opposition could have started with this essay of 1807 , copies of which Fourier sent to Biot and Poisson. Rightly or wrongly, Biot believed that Fourier borrowed from his 1804 article, without now citing him, and was insulted. Poisson also attacked Fourier's mathematics. Biot and Poisson were both ambitious and talented young men who were influenced by Laplace; it seems that the "patron" stayed above this clash.

For his part, Laplace wrote on the propagation of heat in 1809 in an essay that dealt with plenty of other subjects in physics, as the title indicates [Lapl]. For heat, he adopted $^{39}$ the principle of transmission through action at a short distance. He discovered the heat equations, though he accepted Fourier's priority: "I must remark that Mr. Fourier already got to these equations", he added however, "of which the real foundations seem to me to be those that I have presented". In October 1809, Biot published in Mercure de France, a literary magazine, an article [BioC] summarising Du calorique rayonnant (Of radiating heat) by Pierre Prévost. In this article, he cited a number of scientists, such as Laplace, Lavoisier (1784), Pictet, Rumford and Leslie and explained Prévost's perspective on radiation, describing specific examples to grasp the phenomenon. Until this point, there was not much here to anger Fourier, who, at the time, was not particularly concerned with radiation. But Biot continued:

This is what led a major geometrician (2) [this (2) refers to a footnote of Biot's article, see below] to extend radiation even to the interior of solid bodies; [...] These considerations immediately provided the mathematical laws of transmitting heat in accordance with phenomena and they have the advantage of removing an analytical difficulty that, until this point, has stopped all those who wanted to calculate the propagation of heat through bodies.

38 [GraF, end of ch. 8, p. 184]

39 [Lapl, Note, p. 290 in Euvres de Laplace, t. XII]
Fourier's name appeared not once in the dozen pages of Biot's article. The note (2) was phrased as follows: “(2) Mr Laplace. What has been related here has been gathered from his conversations and form the subject of a work on heat that he has not yet published". Actually, Laplace had already "read" a text at the Académie during the meeting of Monday 30 January 1809 , which was the prelude to the 1810 essay [Lapl]. Biot actually credited Laplace with all the recent discoveries on the theory of heat and he implicitly contested the validity of Fourier's results, without citing him: "an analytical difficulty $[\ldots]$ that has $[\ldots]$ stopped all who [...]". This passage in particular shocked and nettled Fourier. He responded and compiled very sharp criticisms of Biot in letters to several correspondents. ${ }^{40,41}$ Even if he was loath to cause controversy in scientific reviews, Fourier was also a politician with his supporters: to advance his cause, he knew to write to those with influence (he also learned that silence is most effective in certain circumstances). He also communicated with Laplace in highly civil terms, although he still held a grudge that led him to forget to cite Laplace throughout the entirety of his major work $[\mathrm{Fo}-\mathrm{C}]{ }^{42}$

Biot opposed Fourier, but he was quite quick to leave his research on the theory of heat, unlike Poisson. Nevertheless, Biot discussed heat in his large, four-volume work Traité de physique expérimentale et mathématique (Treaty on experimental and mathematical physics) in $1816 .{ }^{43}$ In a lengthy footnote on page 669 in volume 4, he claimed to have been the first to establish the correct equation for the stationary state in his 1804 essay. Fourier had no difficulty in contradicting this claim of precedence. ${ }^{44}$ In the same footnote, Biot also cited Laplace as having discovered the general heat equations, whereas Fourier only "rediscovered" them: omitting that of 1807, he mentioned Fourier's award-winning essay of 1812, which followed Laplace's essay. To conclude, Biot highlighted the works by Poisson, in which he praised the handling of the problem of heat as being superior to that of Fourier's, which used trigonometric series. No trace of the controversy can be found after 1816, at least in Fourier's lifetime. However, at 68 years old, Biot still had some venom to let out: in an article in the Revue des Savants in 1842 , which was dedicated, according to the title, to the publication started in 1836 of the Comptes Rendus Hebdomadaires de l'Académie, he lashed out at the leadership of permanent secretary Fourier, the quality of his eulogy for Laplace, etc.

\section{$5 \quad$ Parisian Life}

Kahane $^{45}$ talks about competitors of Fourier, namely Cauchy, and especially Poisson, whose mathematics is rehabilitated by him (if this were necessary); he may want to balance GrattanGuinness, who said very negative things about Poisson in one of his books [GraF]. Poisson has been a competitor, if not an opponent of Fourier. In a seminar in 2018, I heard

\footnotetext{
40 [D-R, ch. VI, p. 340]

41 [Heri, Appendix, letters XVII and XVIII]

42 [D-R, ch. VIII, p. 479])

43 [GraC, 7.7, 9.4.2]

44 [Heri, ch. 7, p. 158]

$45[\mathrm{~K}-\mathrm{L}, 3.5]$
} 
Gilles Lebeau talking about Poisson as a great man. It is funny to have a look at how he was seen by a future great man, the young Abel, 24 years old, sometimes living in Paris (to be precise, from 10 July to 29 December 1826). Fortunately for Frenchmen like me, a collection of Abel's letters in French translation appeared in [AbeM], published in 1902 to the centenary of his birth (part of these letters already appeared in 1881, in French with slightly different translations, see [AbeO]). Abel was hoping to get into contact with French mathematicians, but the summer was not the best period to do so. He writes:

I have only seen Poisson on a promenade; he looked quite self-satisfied. It is said, though, that he is not. (Lettre XVI, to Hansteen, 12th of August 1826).

and later:

Poisson is a short man with a nice little stomach. He carries himself with dignity. Like Fourier. (Lettre XVIII, to Holmboe, 24th of october 1826).

As regards physical aspects, Abel certainly had a preference for young Parisian girls, who are mentioned in the same letter of the 24 October to his Norwegian friend. Abel's letters contain several expressions in French, reproduced below in italics. By their private nature, these letters heavily contrast with Fourier's severity, ${ }^{46}$ whose emotional life is not really known (although we know that he was jovial by nature). After having said he likes to see Miss Mars in the theatre, and having talked about the funeral of the great actor Talma, Abel adds the following:

I go sometimes to the Palais Royal which is named by people of Paris as un lieu de perdition. As a large number, there are des femmes de bonne volonté. They are absolutely not indiscreet. All we hear is Voulez-vous monter avec moi mon petit ami; petit méchant. [...] Lots of them are quite beautiful.

Abel ensures meanwhile that, being engaged in Norway, he stays very reasonable. He also notices the following meeting:

[...] Herr Le-jeune Dirichlet, a Prussian who went to talk to me, considering me as a compatriot.

This "Prussian" was born in 1805 in Düren, located at that time in Napoléon's France, between Cologne and Aix-laChapelle, but Düren came back to Prussia after 1815; his grandfather was born in Verviers. ${ }^{47}$ In May 1822, the young German came to Paris in order to study there. In 1825 he showed one case - among two - of the "Fermat's great theorem" for $n=5$, and presented his results to the Académie; the other case was rapidly completed by Adrien-Marie Legendre (and later, by Dirichlet himself, in a paper published in 1828 in the journal "de Crelle"). At the end of 1825, the general Foy, who had given him a comfortable position as preceptor since the summer of 1823 , died and Dirichlet considered leaving France. Dirichlet belonged to a circle of Fourier's "supporters", including Sturm, Sophie Germain, Navier and, a little bit later, Joseph Liouville, about 20 years old. From the editors' comments on Abel's letters,

46 [D-R, épilogue, p. 683]

47 see Jürgen Elstrodt [Elst]
Fourier recommended Dirichlet for his first position at Breslau (named today Wrocław in Poland) in 1827. It is probably under his influence that the arithmetician Dirichlet turned out to study trigonometric series. In his celebrated article [DirC] published in 1829 in French on that subject, he reproduces identically, without explicitly mentioning Fourier's name but by citing "Théorie de la chaleur, No. 232 et suiv.", the equation for the coefficients which can be found at the end of the article 233 of Fourier's book [Fo-C],

$$
\begin{aligned}
& \frac{1}{2 \pi} \int \varphi(\alpha) \partial \alpha \\
&+\frac{1}{\pi}\left\{\begin{array}{l}
\cos x \int \varphi(\alpha) \cos \alpha \partial \alpha+\cos 2 x \int \varphi(\alpha) \cos 2 \alpha \partial \alpha \ldots \\
\sin x \int \varphi(\alpha) \sin \alpha \partial \alpha+\sin 2 x \int \varphi(\alpha) \sin 2 \alpha \partial \alpha \ldots
\end{array}\right\} .
\end{aligned}
$$

Of course, Fourier's work has come close to Dirichlet's kernel $D_{n}$ and to its use: he wrote ${ }^{48}$ indeed - using the outdated function sinus verse - the sum $D_{n}(x)=\sum_{j=-n}^{n} \cos (j x)$ in the equivalent form $\cos (n x)+\sin (n x) \operatorname{cotan}(x / 2)$ and he additionally had an heuristics reasoning to a "Riemann's lemma", and also to the convergence towards $\varphi\left(x_{0}\right)$ of integrals of $\varphi$ multiplied by the translation by $x_{0}$ of these "kernels". Dirichlet made this "reasoning" into proofs.

Does the absence of the name "Fourier" in the paper [DirC] mean that Fourier was such a great man for Dirichlet that naming him was useless? Bearing this in mind, one can nowadays understand his first paragraph:

[...] This property had not escaped the attention of the celebrated geometer who has opened a new field of applications of analysis by introducing ways of expressing arbitrary functions; they are given in the Memoir that contains all his first researches on heat.

Dirichlet's article in the journal "de Crelle", after the title, was introduced in this way:

\section{(By Mr. Lejeune -Dirichlet, prof. de mathém.)}

and dated on the last page: "Berlin, Janvier 1829", one month before his 24th birthday. Later, in German, in an article [DirD] published in 1837 to the mathematical physicists, Dirichlet mentions Fourier and makes explicit his high esteem of him. On the other hand, Dirichlet [DirC] criticises Cauchy, who proposed proofs concerning Fourier series (Mémoire sur le développement des fonctions en séries périodiques, 1827). Bad memories of Paris, from May 1822 to 1826 ? Coming back to the letter of 24 October 1826, Abel wrote:

Legendre is a very nice man but unfortunately "old as stones" [steinalt, in original German]. Cauchy is fou, and one would have nothing to do with him,

but he also adds the following: "although he is nowadays the mathematician who knows how to tackle mathematics." Later, about a memoir entitled Sur une certaine classe d'équations transcendantes, which he had just finished and wanted to present to the Académie, Abel confides:

I have shown it to Cauchy; but he barely had a look at it. And without undue immodesty I dare say that it is good. I am curious to know the opinion of the Institut.

48 [Fo-C, ch. IX, art. 423, p. 562] 
It was precisely the permanent secretary Fourier who would deal with that manuscript, but it was not as good as it could have been. Legendre (who was, albeit an expert, already 74 years old) and Cauchy were appointed as referees in the meeting of 30 October 1826 . Then the process got stuck. Two years later, Carl Jacobi wrote to Legendre, from Königsberg ${ }^{49}$ on the 14 March 1829, in order to obtain news from this memoir, one month before Abel's death. Legendre answered on the 8 April from Paris. He explained that "the memoir was almost not readable, being written in very white ink with badly done characters", and Cauchy and he agreed on asking the author to hand in a more readable copy, something that Abel did not, and the matter did not move forward. According to Legendre, Cauchy bears the greatest responsibility for that:

Mr. Cauchy kept the manuscript without taking care of it [...]. However, I asked Mr. Cauchy to give me the manuscript which I never have had and I will check what I can do to right, if possible, the lack of care that he gave to a work which would have certainly deserved better.

Kahane, ${ }^{50}$ speaking of Fourier, says that Cauchy "was not his friend", which is a nice understatement. It is often written though that Cauchy acknowledged Fourier's authorship of the notation $\int_{a}^{b}$ for the definite integral, taken between $a$ and $b$ : it is as if Georg Cantor, or Karl Weierstrass after 1885, insisted on acknowledging Leopold Kronecker's authorship of his $\delta$ symbol...

\section{Reception of His Work: Riemann}

One can read in several documents that Fourier remained unknown, badly discussed in France - even Victor Hugo had his opinion about that ${ }^{51}$ - in spite of his (slow) recognition by the Académie. His collected works ("ses Cuvres") were belatedly published, in 1888 and 1890. Nevertheless, Dirichlet celebrated him, in French, only seven years after the publication of the book of 1822, and he certainly passed on his high assessment of Fourier's works to Bernhard Riemann. The historical part of Riemann's habilitation thesis [Riem], written in 1854 and published in 1867 after his death, is given by Kahane ${ }^{52}$ in both German and French (translation by L. Laugel [R-L], 1873). From the first page, Riemann states the following:

The trigonometric series, as named by Fourier [...] have a pivotal role in the part of Mathematics dealing with arbitrary functions.

Later, after having recalled d'Alembert, Euler, Bernoulli and Lagrange:

Even after almost fifty years, no decisive progress on the problem of the possibility of the analytic representation of arbitrary functions had been done until Fourier's remark, which gave a new viewpoint on this problem. This has marked the coming of a new era for this part of Mathematics, which soon came to light

49 [JacW, p. 436]

50 [K-L, end of ch. 1]

$51[\mathrm{~K}-\mathrm{L}$, end of ch. 1]

$52[\mathrm{~K}-\mathrm{L}, 5.9]$ in a brilliant way via the great developments of the Mathematical Physics. Fourier noted that, in the trigonometric series [...] the coefficients are given by the formulas

$$
a_{n}=\frac{1}{\pi} \int_{-\pi}^{\pi} f(x) \sin n x d x, \quad b_{n}=\frac{1}{\pi} \int_{-\pi}^{\pi} f(x) \cos n x d x .
$$

[Riemann writes $a_{n} \sin n x+b_{n} \cos n x$, in contrast with what is done nowadays] He saw that these equations can also be used when the function $f(x)$ is arbitrary.

Riemann then refutes Poisson's viewpoint, who, each time he cited these formulas (Riemann takes, as an example, Traité de mécanique from 1833, art. 323, p. 638), referred to a publication by Lagrange in Miscellanea Taurinensia (t. III, 1762-1765). In this long manuscript, Lagrange solves a certain number of equations and differential systems and comes back in the art. 38 to his solution to the problem of vibrating strings (wave equations), where his reasoning is based on $N$ identical masses situated at equidistant points of the string, letting $N$ go to infinity afterwards. The formula cited by Poisson appears in the article 41. Lagrange raises a question there of interpolation on the interval $[0,1]$ by a trigonometric polynomial that is a sum of sine functions.

Given a "curve" $Y(x)$ such that $Y(0)=Y(1)=0$, Lagrange looks for another curve $y(x)=\alpha \sin (x \pi)+\beta \sin (2 x \pi)+\cdots+$ $\omega \sin (n x \pi)$, for large but fixed $n$, which equals the initial curve $Y$ at the points $x_{k}=k /(n+1), k=1, \ldots, n$. He writes his solution (up to some change of notation) as

$$
\begin{aligned}
& y(x)=\sum_{j=1}^{n} 2 Z_{j} \sin (j x \pi) \quad \text { where } \\
& \quad Z_{j}=\frac{1}{n+1} \sum_{k=1}^{n} Y\left(x_{k}\right) \sin \left(j x_{k} \pi\right), \quad j=1, \ldots, n ;
\end{aligned}
$$

Lagrange's reasonings in the previous pages yield the "inverse" equation $y\left(x_{k}\right)=Y\left(x_{k}\right)$, for any $k=1, \ldots, n$. One recognises the direct and inverse transformations of "Fourier", on the group $\mathbb{Z} /(2 n+2) \mathbb{Z}$, restricted to "odd" functions (one could extend the function $Y$ as an odd function on $[-1,1])$. Then, Lagrange decides to set $n+1=1 /(d X)$ and $x_{k}=$ $k /(n+1)=X$. He thus rewrites the equation for $Z_{j}$ as an "integral from $X=0$ to $X=1$ "; doing this replacement in $y(x)$, he gets a kind of Fourier's integral equation (for odd functions, and restricted to a finite degree $n$ ), which, in modern notation, reads as

$$
y(x)=2 \sum_{j=1}^{n}\left(\int_{0}^{1} Y(X) \sin (j X \pi) d X\right) \sin (x \pi) .
$$

Lagrange emphasises that he has found a function $y(x)$ in this way which equals $Y(x)$ at the points $x_{k}=k /(n+1)$, $k=1, \ldots, n$ (and also $k=0, n+1$ ).

There is still one issue: to agree with Poisson's viewpoint against the precedence of Fourier, one has to read a true integral. However, in order to succeed in the above interpolation, Lagrange must keep a finite sum. To Poisson's expected bias with respect to Fourier, even after Fourier's death, Riemann replies with a little lack of sincerity, by refusing to acknowledge, at least in these "Riemann sums", the partition mesh of which tends to 0, the beginnings of Fourier's integral equations! He writes: 
This formula has the same form as Fourier's series, in such a way that, at first glance, confusion can easily be possible; but, this perception only results from the fact that Lagrange used the symbol $\int d X$, where he would today have used the notation $\sum \Delta X$. [...] If Lagrange would have taken the limit with $n$ going to infinity in this equation, he would have arrived at Fourier's result; $[\ldots]$.

Although introduced by Euler in 1755, the notation $\sum$ for finite sums (without bounds, like for the integral at that time) was not common before 1800; Lagrange needed a notation in order to write the double sum in the formula (5) for $y(x)$ in only two lines, the sum in $X=x_{k}$ (thus expressed in terms of integrals from 0 to 1 ), and the one in $j$ which is written as $s_{1}+\cdots+s_{n}$. To this end, he would have used the notation $\int$. Riemann adds that Lagrange did not believe in the possibility of representing arbitrary functions by trigonometric series and therefore, he did not arrive at a derivation of Fourier's formulas: "Of course, nowadays, it seems to be scarcely conceivable that Lagrange did not obtain Fourier's series from his sum formula". He goes on:

It is Fourier who has first understood in a complete and exact way the nature of trigonometric series.

He then proceeds with the first general proofs of Fourier's theorem, i.e., with Dirichlet's article [DirC].

\section{Mathematical Physics or Pure Mathematics?}

It is beyond my expertise to comment on the obvious seminal character, affirmed in the title of Dhombres and Robert's book [D-R], of Fourier's work with respect to mathematical physics. It is clear that Fourier wanted to develop the understanding of the world and derive equations for an extraordinarily important natural phenomenon, as Newton did for the gravitational attraction. His ambitions are high, and the mathematical-physics viewpoint is already affirmed in the first lines of the preliminary discussion (Discours préliminaire) of the Théorie analytique $[\mathrm{Fo}-\mathrm{C}]:^{.53}$

Like gravity, the heat penetrates all substances of the universe $[\ldots]$ The aim of our manuscript is to state the mathematical laws of such a phenomenon. This theory will be one of the most important field of general physics.

and in the middle of the preliminary discussion:

The thorough study of nature is the most fertile source of mathematical discoveries.

Fourier stresses at the beginning of the Discours that he himself had taken numerous measurements in support of his theory, with the most precise instruments. It was not his intention to take into account the particular aspects that can characterise heat; he avoided having to distinguish between the different forms of propagation - by contact, diffusion or radiation. Biot shared this point of view in 1804 [BioM]:

I will not examine here whether heat is a body or if it is nothing but the result of the internal motion of material's particles, but rather, assuming that its effects are measurable by the thermometer, once they become noticeable, I will search the laws of its propagation.

53 cited in [D-R, Annexe V, p. 717] and [K-L, 2.5]
In his essay of 1807 , and more definitely since the awardwinning essay of $1812,{ }^{54,55}$ Fourier based his approach on the notion of heat flux, which may seem natural today but is in fact his invention. Let there be a point $P$ inside a homogeneous solid, a time $t$ and a direction given by a unitary vector $u$. Consider an infinitesimal circle $d \sigma$ with centre $P$ and contained in an affine plane that is orthogonal to $u$. Let $d S$ be the area of $d \sigma$ and $d q$ the quantity of heat that crosses $d \sigma$, in the direction of $u$ and in a duration $d t$ after the date $t$. The heat flux at the point $P$, at the time $t$ and in the direction $u$ is the limit $\phi_{u}$ of the quotient $d q /(d S d t)$. In modern terms, Fourier's fundamental law indicates that this flux is expressed as a scalar product $\phi_{u}=-\kappa \nabla v \cdot u$, where $v$ is the temperature and where the coefficient $\kappa>0$ depends on the solid. He put it in other words ${ }^{56}$ in the articles 96 and 97 of the section Mesure du mouvement de la chaleur en un point donné d'une masse solide (Measuring the movement of heat at a given point of a solid mass). In fact, there are no vectors in Fourier's text, only rectangular coordinates. The flux in the general case is determined by three values, the fluxes in the directions of increasing $x, y$ and $z$. In his book, he gets there very progressively, starting with uniform movements of heat, and at first even uniform in the direction of a coordinate axis (ch. I, sec. 4 and sec. 7). Fourier returns to the flux in art. 140, before deducing from it the heat equation in art. 142.

Of course, Fourier did not write the heat equation without including the characteristic physical constants of the given body. So, for the equation that governs the temperature $v$ inside a solid, he writes

$$
\frac{\partial v}{\partial t}=\frac{K}{C D}\left(\frac{\partial^{2} v}{\partial x^{2}}+\frac{\partial^{2} v}{\partial y^{2}}+\frac{\partial^{2} v}{\partial z^{2}}\right),
$$

where $D$ is the density, $K$ the inner conductibility and $C$ the specific heat. Furthermore, he is among the first ones to pay attention to the dimension equations involving positive or negative powers of physical dimensions, the length, the time and, for him, the temperature. ${ }^{57}$ Today we would have the mass instead of the temperature, expressing heat by a mechanical equivalent.

Fourier defines the boundary condition for his partial differential equation (6): the equation at the border of the solid is, in modern notation,

$$
\nabla v \cdot n=-\frac{h}{K}\left(v-v_{e}\right)
$$

where $n$ is the outgoing normal vector, $h$ the exterior conductibility and $v_{e}$ the temperature outside of the solid ${ }^{58}$ (Fourier supposed $v_{e}=0$ ).

Dhombres and Robert ${ }^{59}$ point out that still at the present time, teaching of heat propagation follows Fourier's approach. They remark:

[...] the practically unchanged manner in which we formulate, present and demonstrate today the fundamental results that Fourier enounced [...],
54 [Heri, ch. 9]
55 [Fo-P, art. 18 and next]
56 [Fo-C, ch. I, sec. VIII, p. 89]
57 [D-R, ch. VIII, p. 515-518]
58 [Fo-C, art. 146 p. 138 and art. 147]
59 [D-R, ch. IX, p. 626] 
stating that in the major manuals of physics from the middle of the $20^{\text {th }}$ century (Georges Bruhat, Richard Feynman and others) the calculations given for a metal plate or a ring, for example, are essentially similar to Fourier's. They complement that today, we do not demonstrate the law of heat diffusion in solids any more, partly because we do not know how to do it from the first principles of atomic physics, while Fourier's reasoning seems not to be atomistic enough nowadays.

After the consecration, Fourier published between 1817 and 1825 his "contributions à l'étude de la chaleur rayonnante" (contributions to the study of radiating heat), the phenomenon of radiation by which heat (or cold) can propagate over a distance without any contact. But this subject had to wait for certain progress in physics to take place at the end of the $19^{\text {th }}$ century (Stefan's law in 1860 , rediscovered by Boltzmann in 1879), before more complete answers could be obtained. In 1824, Sadi Carnot, son of Lazare Carnot, published his Réflexions sur la puissance motrice du feu (Reflections on the driving power of fire), but Fourier did not get familiar with this research - and he was not the only one in the 1825-1830 years. Carnot's publication, however, has contributed to the birth of thermodynamics.

Kahane has written several articles on Fourier. He mentions the opposed viewpoints of Fourier and certain "pure" mathematicians. He cites ${ }^{60}$ a famous extract from a letter that Jacobi wrote to Legendre, sent on 2 July 1830, a little after Fourier's death in mid-May 1830. Jacobi addressed Legendre in French, excusing himself here and there for the possible incorrectness of his language use. Jacobi's letters were transcribed by Joseph Bertrand [JacL]. We have to trust Bertrand and his editor for the exactitude of the transcription: the letters were burned during the Paris Commune in 1871, as did Bertrand's house in the Rue de Rivoli.

Jacobi writes: 61 "I was delighted to read Mr. Poisson's report on my work, and I think I can be very pleased with it; he seems to have presented [my work] very well. But Mr. Poisson should not have reproduced in his report the not very suitable statement of the deceased Mr. Fourier, reproaching Abel and me for not having paid prime attention to the movement of heat." He added:

It is true that Mr. Fourier was of the opinion that the main aim of mathematics was its public utility and the explanation of natural phenomena; but a philosopher like him should have known that the sole purpose of science is the honor of the human mind, and that in this regard, a question about numbers is as worthy as a question about the system of the world.

Jacobi continued by expressing his regret at Fourier's death: "Such men are rare today, even in France, they cannot be replaced that easily." He closed by asking Legendre to give his "regards to Miss Sophie Germain whose acquaintance I had the good fortune to make, and let me know about her condition". Sophie Germain suffered from a "long disease", she died the following year.

Four years earlier, Abel had written to Holmboe (24 October 1826) that he regretted Fourier's and other French mathematicians' commitment to applied sciences:

$60[\mathrm{~K}-\mathrm{L}, 4.6]$

61 [JacW, vol. 1, p. 454]
Chronology

Joseph-Louis Lagrange 1736-1813

Gaspard Monge 1746-1818

Pierre-Simon Laplace 1749-1827

Adrien-Marie Legendre 1752-1833

Lazare Carnot 1753-1823

François Budan de Boislaurent 1761-1840

Sylvestre-François Lacroix 1765-1843

Joseph Fourier 1768-1830

Napoléon Bonaparte 1769-1821

Jean-Baptiste Biot 1774-1862

Marie-Sophie Germain 1776-1831

Jacques-Joseph Champollion-Figeac 1778-1867

Siméon Denis Poisson 1781-1840

Henri Beyle (Stendhal) 1783-1842

Friedrich Wilhelm Bessel 1784-1846

Claude Louis Marie Henri Navier 1785-1836

Augustin Louis Cauchy 1789-1857

Jean-François Champollion 1790-1832

Nicolas Sadi Carnot 1796-1832

Niels Henrik Abel 1802-1829

Jacques Charles Sturm 1803-1855

Carl Gustav Jacobi 1804-1851

Gustav Lejeune-Dirichlet 1805-1859

Joseph Liouville 1809-1882

Évariste Galois 1811-1832

Bernhard Riemann 1826-1866

[Cauchy] is by the way the only one to work on pure mathematics at present. Poisson, Fourier, Ampère etc. focus on nothing else but magnetism and other subjects of physics.

Poisson, Fourier, André-Marie Ampère: three professors at the École Polytechnique. We could ask ourselves if the scientific pre-eminence of the École in France during the first half of the $19^{\text {th }}$ century, with its mission to educate mainly engineers, could be one of the reasons for the decline of French mathematics in the middle of the same century, when it is surpassed by the German University. Joseph Ben-David [B-Da] rather incriminated the teaching practice at the École, which did not keep up with the progress of science and forgot one of the institution missions fixed by the founding fathers - the second term of the grandiose maxim of 1804: "Pour la Patrie, les Sciences et la Gloire" (For the Country, the Sciences and the Glory).

Fourier's mathematical fame suffered an eclipse in France in the second half of the $19^{\text {th }}$ century, but harmonic analysis, Fourier series and the Fourier transform have found their place in the "very pure" French mathematics of the $20^{\text {th }}$ century. Kahane has contributed to this by his articles and books dealing with most specialised subjects regarding thin sets, that result from an exclusively mathematical study of Fourier series. A little paradoxically, the same Kahane turned himself into a defender of Fourier's mathematical physics. Regarding the temporary "eclipse", he observes, in his article [KahQ] of 2014, a forceful return of Fourier's standpoints on the occasion of a mathematics-physics convergence in our days:

This underestimation of Fourier does now belong to the past. It could only maintain itself in France thanks to a divorce between mathematics and physics, which is completely overcome today. One of the biggest French universities, in Grenoble of course, carries the name of Joseph Fourier.

We conclude with Kahane, who writes in the same text: 
When I was young, and it is still the same among the young people, "the honor of the human mind" sounded more glorious than "the thorough study of nature". However, Fourier's philosophy seems to me to be closer than ever to the actual evolution of mathematics and their - sometimes termed "unreasonable" impact on the natural sciences.

Most of the "historical" references below, like Fourier's Théorie analytique de la chaleur or the Mémorial compiling Abel's letters, are nowadays easy to access, thanks to websites like EuDML, Gallica, archive.org and many others.

\section{Acknowledgements}

I thank Jean Dhombres who permitted me to exploit his book with Jean-Bernard Robert [D-R], and gave me the honour of reading a preliminary version of this article, allowing me to correct some of my mistakes. The two referees of the SMF contributed to significant improvements of the manuscript, making the text clearer and more precise while emphasising important points. Special thanks also to the Institut de Mathématiques de Jussieu-Paris Rive gauche and Sorbonne Université for providing me with all the resources to do this work.

The EMS Newsletter thanks La Gazette des Mathématiciens for authorisation to republish this text, which is an english translation of the paper [La Gazette des Mathématiciens, $\mathrm{N}^{\circ}$ 158, pp. 7-24, Octobre 2018].

\section{Bibliography}

[AbeU] N. H. Abel, Untersuchungen über die Reihe: $1+\frac{m}{1} x+$ $\frac{m \cdot(m-1)}{1 \cdot 2} \cdot x^{2}+\frac{m \cdot(m-1) \cdot(m-2)}{1 \cdot 2} \cdot x^{3}+\ldots \ldots$ u. s. W., Journal für die reine und angew. Math. 1, 311-339 (1826).

[AbeO] N. H. Abel, Euvres complètes de Niels Henrik Abel. New Edition published by MM. L. Sylow and S. Lie via a funding of the Norwegian state. De Grøndahl \& Søn, Christiana, 1881.

[AbeM] N. H. Abel, Mémorial publié à l'occasion du centenaire de sa naissance. Jacob Dybwad, Kristiania; GauthierVillars, Paris; Williams \& Norgate, Londres; B. G. Teubner, Leipzig, 1902.

[B-Da] J. Ben-David, The rise and decline of France as a scientific centre, Minerva 8, 160-179 (1970).

[BioM] J.-B. Biot, Mémoire sur la propagation de la chaleur, et sur un moyen simple et exact de mesurer les hautes températures, Journal des Mines 99, 203-224 (1804-1805); and also, Bibliothèque Britannique 27, 310-329 (1804).

[BioC] J.-B. Biot, Du calorique rayonnant, par Pierre Prévost, Mercure de France 38, 327-338 (1809).

[Boro] J. Borowczyk, Sur la vie et l'œuvre de François Budan (1761-1840), Historia Math. 18, 129-157 (1991)

[Bott] U. Bottazzini, The Higher Calculus: A History of Real and Complex Analysis from Euler to Weierstrass. SpringerVerlag, New-York, 1986.

[D-R] J. Dhombres et J.-B. Robert, Joseph Fourier, 1768-1830. Créateur de la physique-mathématique. Collection Un savant, une époque, Belin, Paris, 1998.

[DirC] G. Lejeune Dirichlet, Sur la convergence des séries trigonométriques qui servent à représenter une fonction arbitraire entre des limites données. Journal für die reine und angew. Math. 4, 157-169 (1829).

[DirD] G. Lejeune Dirichlet, Ueber die Darstellung ganz willkührlicher Funktionen durch Sinus- und Cosinusreihen, Repertorium der Physik, 152-174 (1837).
[Éc-N] L'École Normale de l'an III. Vol. 1, Leçons de mathématiques. Laplace-Lagrange-Monge. Sous la direction de Jean Dhombres. Dunod, Paris, 1992. Online version: Éditions Rue d'Ulm via OpenEdition, 2012.

[Elst] J. Elstrodt, The Life and Work of Gustav Lejeune Dirichlet (1805-1859), in Analytic number theory. A tribute to Gauss and Dirichlet. Proceedings of the Gauss-Dirichlet conference, Göttingen, Germany, June 20-24, 2005. Edited by William Duke and Yuri Tschinkel. Clay Mathematics Proceedings 7, 1-37, Amer. Math. Soc., Providence, RI; Clay Mathematics Institute, Cambridge, MA, 2007.

[Fo-P] J. Fourier, Sur la propagation de la chaleur, memoir presented at the Académie des Sciences in December 1807. Unpublished, reproduced and commented in [GraF].

[Fo-C] J. Fourier, Théorie analytique de la chaleur. Firmin Didot, Paris, 1822

[Fo-R] Joseph Fourier (1768-1830), de la Révolution française à la révolution analytique. Sous la direction de Jean Dhombres. To be published by Hermann.

[GraF] I. Grattan-Guinness, in collaboration with J. R. Ravetz, Joseph Fourier 1768-1830. A survey of his life and work, based on a critical edition of his monograph on the propagation of heat, presented to the Institut de France in 1807. The MIT Press, Cambridge, Mass.-London, 1972.

[GraC] I. Grattan-Guinness, Convolutions in French mathematics, 1800-1840: from the calculus and mechanics to mathematical analysis and mathematical physics. Science Networks. Historical Studies. Birkhäuser Verlag, Basel, 1990.

[Heri] J. Herivel, Joseph Fourier: The Man and the physicist. Clarendon Press, Oxford, 1975.

[JacL] C. G. J. Jacobi, Lettres sur la théorie des fonctions elliptiques, (publiées par Joseph Bertrand), Annales Scientifiques de l'É.N.S 6, 127-175 (1869).

[JacW] C. Jacobi, C. G. J. Jacobi's gesammelte Werke, G. Reimer, Berlin, 1881-1891.

[KahQ] J. P. Kahane, Qu'est-ce que Fourier peut nous dire aujourd'hui? Gazette des mathématiciens 141, 69-75 (2014).

[K-L] J.-P. Kahane et P. G. Lemarié, Séries de Fourier et ondelettes. Nouvelle Bibliothèque Mathématique, Cassini, Paris, 1998, 2016.

[Körn] T. W. Körner, Fourier Analysis. Cambridge University Press, Cambridge, 1988.

[Lapl] P. S. Laplace, Mémoire sur les mouvements de la lumière dans les milieux diaphanes, Mémoires de l'Académie des sciences, Ire Série, T. X, (1810); dans les Euvres complètes, t. XII, 267-298.

[Mass] F. Masson, L'expédition d'Égypte et la "Description", Bulletin de la SABIX 1, (1987).

[Riem] B. Riemann, Ueber die Darstellbarkeit einer Function durch eine trigonometrische Reihe, Dreizehnter Band der Abhandlungen der Königlichen Gesellschaft der Wissenschaften zu Göttingen, 1867.

[R-L] B. Riemann, Sur la possibilité de représenter une fonction par une série trigonométrique, Bulletin des Sciences Mathématiques et Astronomiques 5, 20-48 (1873).

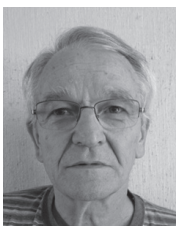

Bernard Maurey [bernard.maurey@imj-prg. fr]. Born in 1948, student of the École Polytechnique in 1966. Professor at the University Paris 7-Denis Diderot until his retirement in 2011. Has been working mainly on the Theory of Banach spaces, then on geometric and functional inequalities. 